\title{
Orientaciones profesionales de los comunicadores sociales
}

\section{Professional orientations of the social communicators}

\author{
Emmily Nathalie Rivadeneira Lara \\ Universidad Politécnica Salesiana, Ecuador \\ Tonny Leonardo Montoya Carrillo \\ Universidad Politécnica Salesiana, Ecuador
}

Autor por correspondencia: emmily_rivadeneira.1@hotmail.com,tmontoya@ups.edu.ec

Fecha de recepción: 9 de Febrero de 2017 - Fecha de aceptación: 28 de Abril de 2017

\section{Resumen}

El siguiente trabajo de investigación expone la presente situación de los comunicadores sociales en la ciudad de Guayaquil, en el ámbito político, social, laboral y académico. Se destaca el perfil profesional que posee cada comunicador en los distintos campos profesionales en los que se encuentra inmerso actualmente debido a las transformaciones del mercado laboral, cambios que han permitido al comunicador adaptarse profesionalmente en áreas concebidas gracias a la evolución tecnológica del nuevo siglo, situando la investigación al conocimiento de las diversas ramas de comunicación, tales como el Periodismo Digital, Community Management, Relaciones Públicas, Comunicación Organizacional y Periodismo a través de medios tradicionales. Áreas profesionales que se representan como alternativas ocupacionales en el mercado laboral de un comunicador social en la actualidad.

Palabras clave: comunicadores sociales; orientación profesional; alternativas laborales; ramas de comunicación; cambios tecnológicos

\begin{abstract}
The following research paper exposes the present situation of social communicators in the city of Guayaquil, in the political, social, labor and academic field. It emphasizes the professional profile that each communicator possesses in the different professional fields in which he is currently immersed due to the transformations of the labor market, changes that have allowed the communicator to adapt professionally in areas conceived thanks to the technological evolution of the new century, placing Research to the knowledge of the various branches of communication, such as Digital Journalism, Community Management, Public Relations, Organizational Communication and Journalism through traditional media. Professional areas that are represented as occupational alternatives in the labor market of a social communicator today.
\end{abstract}

Key words: social communicators; career counseling; job alternatives; branches of communication; technological changes 


\section{Introducción}

Uno de los procesos más significativos del ser humano, se da mediante la comunicación, esta actividad como tal, se incluye desde la concepción del hombre, hasta el final de su existencia. Hablar de comunicación, es departir los usos y necesidades de esta actividad, primero como técnica de expresión y luego como método esencial de conexión entre seres, quienes a través de la información buscan causar una reacción entre los elementos que utilizamos en ella: emisor, mensaje, receptor.

La comunicación, ha sido un paso primordial en la vida del ser humano, un proceso de interacción que se ha redefinido al pasar del tiempo, y franqueó de una acción bidireccional, a una técnica que permite mantener una conexión a nivel personal e interpersonal con el otro.

Eggers-Brass, (2010) cataloga a la comunicación como: “una relación, un proceso de intercambio" en donde además "el cuerpo, los gestos, los colores, las imágenes, los silencios y hasta la distancia entre las personas comunican algo y significan algo en la cultura que comparten"; o como también lo menciona Villegas (2014) "la comunicación estudia las relaciones comunicativas del hombre en sociedad, en todas sus dimensiones, espiritual, cultural, política, económica, científica, física, etc.”.

En la sociedad actual comunicación es lo que vemos, oímos, percibimos y callamos, generalmente, comunicación lo es todo. Con la evolución y transformación de la sociedad, el concepto de comunicación, adoptó el manejo de la más media, una concepción que se generó desde la invención de la imprenta y posterior uso de los primeros periódicos en el viejo continente, la inserción de canales que generaban y emitían información (medios de comunicación) hasta la reciente llegada de los medios tecnológicos.

La comunicación acoge tanta importancia en el mundo y la cotidianidad, que empresas y grupos los han visto como una oportunidad de vincularse con las masas, es aquí donde intervienen los denominados medios de comunicación, las comunicaciones internas $\mathrm{u}$ organizacionales y las relaciones públicas.

Las Ciencias de la Comunicación son hoy en día una disciplina central para entender el medio eminentemente cultural en el que se forjan las sociedades. Abarcan un amplio espectro de interacciones subjetivas: desde la comunicación diaria entre personas o grupo de personas, en sus más diversas dimensiones, institucionales o comunitarias, pasando por el análisis de la propiedad de medios de comunicación masivos, los mensajes emitidos, los marcos legales que la regulan y los sujetos que reciben esos mensajes, tanto en términos grupales como individuales. También estudian los efectos que produce la comunicación sobre estos sujetos y las reacciones de los mismos, con toda su complejidad. (Com, Ackerman, \& Morel, 2011, p. 17)

Sin embargo, las actividades planteadas desde la comunicación no son monótonas y mucho menos unidireccionales, existen varias áreas que desempeñan funciones de gran importancia y que han permitido desde este punto, transformar la concepción de comunicación, no como un hecho aislado de intercambio de ideas, más bien lo orienta a un proceso que se ha profesionalizado en diferentes ramas de estudio como: la comunicación social, el periodismo, 
las relaciones públicas, la comunicación institucional u organizacional, el periodismo digital, los medios comunitarios y el manejo de comunidades internautas o redes sociales.

Específicamente la comunicación social, "en sentido estricto, se define como el conjunto de actos de comunicación destinados a modificar las representaciones, los comportamientos o a reforzar las solidaridades" (Vilches, 2014) trabaja conjuntamente con la sociedad adaptando espacios de interrelación que permitan a través de la retroalimentación continua, generar y distribuir de forma correcta la información, logrando proponer y gestionar soluciones en beneficio de los individuos que conviven en un grupo social. Esta actividad se realiza entre el gestor, que se lo conoce como el comunicador social, la comunidad y los entes gubernamentales.

\section{Discusión teórica}

\section{La Comunicación Social en la Actualidad}

El comunicador social, resulta ser el gestor o mediador dentro del campo de la comunicación, sirviendo como fuente de información y expresión entre los medios masivos y la cultura en general. Difunde, representa y proyecta la información con el uso de estrategias comunicativas que fortalecen la relación entre las distintas entidades y el público objetivo.

La comunicación acorde con los cambios sociales, gestiona de forma conjunta sus actividades y participa individualmente en los distintos espacios sociales, conformando un componente importante en cuanto a la difusión de contenidos, un concepto que ha transformado el ejercicio de la comunicación.

(...)la comunicación significa hoy el espacio de punta de la modernización, el motor mismo de la renovación industrial y las transformaciones culturales que nos hacen contemporáneos del futuro, ya que, asociada al desarrollo de las tecnologías de información, la comunicación nos proporciona la posibilidad de alcanzar al fin el tren de la definitiva modernización industrial, de la eficacia administrativa, de las innovaciones educativas y hasta del avance democrático que entrañarían las virtualidades descentralizadoras de la informática. (Barbero, J.M., 2009, p.117-118)

La inserción de la tecnológica influye en todas las áreas que ejerce el ser humano, y simboliza para el comunicador social una herramienta de manejo instantáneo en el envío de información, sin dejar de lado los medios tradicionales que utiliza para la información que de cierta forma es más detallada y completa.

En los últimos años los avances teóricos en el campo de la comunicación han surgido más de los aportes de los estudios culturales que de la propia agenda de la mass communication research. Los modernos estudios culturales han sabido abandonar el antiguo aislamiento entre disciplinas, al integrar a sus metodologías los conocimientos de la antropología, la semiótica y la sociología, tanto en la investigación como en la formación de expertos. (Moragas, M. 2009, p. 20)

Es así que en medio del cambio social de la última generación, la comunicación por su parte responde a incluir los espacios y aportes culturales de las nuevas tecnologías, Delgado, C. 
(2008) menciona a la comunicación social como el "campo de estudio de las ciencias de la comunicación", en donde debe estar incluido Internet y todo lo que la red concierne en cuanto al contenido que es publicado; desde los blogs, las redes sociales (Facebook, MySpace, etc.), los podcasts, canales de YouTube, y todo lo que se trate con un lenguaje distinto y que maneje conceptos diversos de la comunicación convencional, contempladas como lo manifiesta el autor: "bajo estas necesidades de generar contenido realizados para estas nuevas exigencias del público nativo y no-nativo de Internet". (Delgado, C. 2008, p.186)

Estos espacios convertidos en la mayor fuente recurrente del público, toman relevancia en el ámbito social y profesional, son el punto de análisis de muchas facultades de comunicación en las cuales se pretende direccionar esta sinergia tecnológica a las diferentes ramas u orientaciones profesionales existentes, Castillo, E. y Tapia, M. (2006), mencionan su punto de vista al respecto, y hacen alusión al concepto de comunicólogo, como alguien que "profesa la comunicología o tiene en ella especialidades y conocimientos" esto, según el concepto de la Lengua de la Real Academia Española, en donde también encontramos lo que la comunicología proyecta, "una Ciencia Interdisciplinaria que estudia la comunicación en sus diferentes medios, técnicas y sistemas" y que en el presente se trabaja desde distintas dimensiones profesionales:

En la actualidad, el campo profesional del comunicólogo se diversifica y no se centra únicamente en los medios. Pese a que en los planes de estudio de las licenciaturas se sigue conservando esta idea, los alumnos ingresan a ellas por percibir su relación con los medios de comunicación, y por lo tanto la relacionan con una profesión práctica. Pensamos que el campo profesional ha cambiado y se ha diversificado de manera más acelerada que los planes de estudio de las escuelas de comunicación, ya que se inicia un proceso de generación de prácticas profesionales emergentes del comunicólogo, que son las que deben impulsarse, como las con las referidas a la comunicación de las organizaciones, comunicación cultura, cultura y desarrollo; contextos de la comunicación educativa, comunicación urbana, comunicación y difusión del conocimiento científico, comunicación legal (régimen de medios con la firma del TLC), comunicación y nuevas tecnologías comunicativas, comunicación educativa, etc., y otras prácticas más que el comunicólogo debe ejercer en el sector público, privado y social. (Castillo, E. y Tapia, M. 2006, p. 11)

Toda esta amplia gama de acciones y oportunidades del comunicador social pretende ser una guía para que el practicante o quien ejerce la profesión pueda comprender que la oferta laboral no es para nada escasa, sino que a medida que la comunicación global se desarrolla, también se amplifican las ocupaciones en las cuales un profesional afín puede participar y formar parte, estas opciones como: relaciones públicas, comunicación organizacional, periodismo digital y servicios de comunicación en redes sociales (Community Manager).forman parte de la actual demanda en el mercado laboral y forman parte de la oferta académica de las facultades de comunicación.

\section{Campos de acción del comunicador social}

A lo largo de las últimas décadas, la comunicación de masas y su globalización ha logrado que los medios tradicionales como la televisión, radio y prensa escrita aparezcan en todo el aparato sistemático de expresiones mediáticas, abarcando un amplio espectro social, político y 
económico, y generando un ambiente de confianza y credibilidad ante estos. Los aportes y estudios de la comunicación han surgido como parte primordial del desarrollo de la sociedad en donde intervienen distintas ramas o campos de acción. En primera instancia el periodismo, una actividad profesional que consiste en captar y generar información. La Real Academia Española (RAE), lo conceptualiza como la "captación y tratamiento, escrito, oral, visual o gráfico, de la información en cualquiera de sus formas y variedades". Caloca, E. (2010) destaca por su parte que:

El periodismo tiene como principal propósito informar, pasando a un segundo término la orientación, la diversión y la difusión de servicios. Sólo que esa información deberá ser verídica, objetiva y oportuna sobre todo, deberá ser sobre acontecimientos, cosas o personas que influyan en la vida de una comunidad, en la cual se ejerza dicha profesión. (Caloca, E., 2010, p.24)

El periodismo es una carrera vocacional muy antigua, ha incidido en todos los espacios sociales de distintas naciones del mundo, llevando consigo la misma responsabilidad por conocer y dar conocer la verdad, divulgada a través de los distintos medios de comunicación que a lo largo del tiempo fueron reapareciendo. La prensa, la radio y finalmente la televisión, si nos centramos en los medios tradicionales la cual ha tenido como función principal según lo menciona Caloca, E. (2010) "satisfacer la necesidad que tiene el ser humano de estar informado. Esta necesidad social de la información crece y se diversifica abarcando actividades más amplias, en cuanto que la complejidad de la estructura social se sensibiliza y se complica. (Caloca, E., 2010, p.24)

Sin embargo no es solo a través del periodismo que podemos mantener un sentido de comunicación equilibrada, pues sí, se acepta el hecho que por medio del periodismo la sociedad está más vinculada con los entes gubernamentales, comerciales y políticos que la conforman, pero dentro de las instituciones quienes tienen cabida a ejercer y manejar la comunicación, dividen sus funciones a otros campos de acción comunicacional tales como la comunicación organizacional y las relaciones públicas, un área que toma relevancia a finales del siglo xx. Las relaciones públicas como lo menciona Di Génova, E. (2000):

Ciencia que estudia el proceso de interacción comunicacional a través del cual una entidad se vincula táctica y estratégicamente con los diferentes públicos. Implementa técnicas específicas de relacionamiento interpersonal y corporativo; y finalmente, coadyuva al posicionamiento de una imagen institucional sólida y basada en valores. (Di Génova, E. 2000, p.11)

Trabajar en esta rama de la comunicación permite generar estrategias que impulsen y vinculen a los públicos con empresas, marcas o entidades que quieren dar a conocer sus productos o servicios, en este sentido la comunicación significa un factor primordial que debe ser trabajado en todo momento y en todo sentido.

El trabajo de esta ciencia consiste en, mediante profundos conocimientos en ciencias económicas, sociales, empresariales, políticas y la aplicación de éstas a técnicas de comunicación unida a gestiones personales, difundir, propagar e informar estratégicamente a tiempo y en el momento oportuno, sobre las personas, mercados, situaciones u organizaciones en función de la 
imagen que desprendamos en la zona de influencia en donde ejercemos nuestra actividad, para que se nos respete y diferencie del resto, generando credibilidad y confianza por la calidad y contenidos de nuestros productos, servicios, organizaciones u otros. (Barquero, J.M., 2005, p.2)

Asimismo las relaciones públicas en vinculación con los medios de comunicación generan otros beneficios para la empresa o institución, los cuales se centran en la publicity, que consiste:

(...) en conseguir que los medios de comunicación hablen de la empresa sin que esta pague por ello, una práctica que sigue siendo muy común actualmente. Para conseguirlo se informa a los periodistas de las novedades de la empresa, a través del envío de notas de prensa y de la organización de actos, entre otras técnicas posibles. (Aced, C. 2013, p. 30)

Esta práctica fundamental en la formación de una imagen positiva de la empresa se genera a través de las agencias de relaciones públicas contratadas para este quehacer, o por los departamentos de comunicación creados para esta función. La comunicación organizacional, en este sentido se encarga de realizar la gestión comunicativa de manera estructurada, forjando la creación de un feedback, entre la institución, ONG, o empresa y el público al cual quiere llegar.

La comunicación organizacional se dedica fundamentalmente a las comunicaciones internas, entendidas éstas como un quehacer complejo que va al fondo de las organizaciones de cualquier índole. A las otras tareas comunicacionales, por ejemplo a las que se ocupan de la imagen institucional, se les llama corporativa, institucional o de relaciones públicas. Otros ejemplos son la comunicación gerencial y la comunicación de negocios, entre otras, mismas que requieren de especificación con el fin de que no se confundan los términos. (Rebeil, C., Ruiz, C. 1998, p. 160)

Al igual que en las relaciones públicas, la comunicación organizacional buscar tener un vínculo directo con la prensa, pues de esta manera el trabajo es más fluido, la comunicación adquiere el tipo de retroalimentación que necesita y la marca o empresa obtiene más confianza al momento de dar a conocer sus aportes y desaciertos si se da el caso.

Las relaciones con la prensa es uno de los ámbitos más importantes de la comunicación institucional. Todavía (aunque esto está cambiando), la mayor parte de las acciones de comunicación desarrolladas desde las instituciones están dirigidas a los medios tradicionales. Por eso, haber pasado por alguno de ellos, conocerlos desde dentro, es un valor añadido poderoso para un comunicador: sabe desde los horarios en los que más probabilidad de éxito tiene un comunicado hasta el enfoque que mejor puede encajar; puede acertar con el formato de comunicación más adecuado o la manera de hacer el mensaje más atractivo para el periodista. (Burgueño, J.M, 2014, p. 22)

Pero estos espacios comunicacionales entre públicos internos y externos no terminan sus funciones ahí, la gama de información y aporte social se explaya a las nuevas necesidades que se generan con la revolución tecnológica, la imagen y los espacios ocupados por estos campos de acción tienden a abrir sus zonas de confort tradicional para estar al alcance y a la par con las tecnologías de la información y la comunicación, significando un cambio revelador y al principio 
inmanejable por su versatilidad y amplitud. Es así que se comienza a echar un vistazo a lo que será la labor profesional del comunicador, Rivas, M. (2009) declara que:

"la globalización y la tecnología hacen posible que surja un nuevo perfil de periodista o comunicador, con muchas más posibilidades para la investigación y el intercambio, así como también han determinado la aparición en todo el planeta de medios de comunicación alternativos y medios digitales y junto a ellos, nuevas formas de hacer y percibir el periodismo. (Rivas, M. 2009, p. 5)

El periodismo digital, o ciberperiodismo como también se lo conoce, ha sido durante las dos últimas décadas una especialidad a la cual el periodista ha tenido que acomodarse para estar a la par con la inmediatez en la que se envía y recibe información en nuestros tiempos, la capacidad de investigar, producir y difundir contenidos también se realiza desde los nuevos espacios de divulgación informativa, los cuales de cierta forma han roto con las formas de consumo mediático.

El periodismo en las redes digitales representa una ruptura con los modelos convencionales de producción; combina pautas de medios como la prensa, la radio y la televisión pero con otro enfoque y mayor velocidad; aunque no es sólo la rapidez lo que caracteriza estas prácticas. Su transformación implica la descentralización de los sistemas de producción y, por ende, una pérdida parcial del comando de las cadenas de información de parte de los periodistas y, asimismo, significa la inserción de los usuarios del sistema como productores de contenidos (Echeverría \& Viada, 2014 en Machado: 2007, p. 54-55).

Además de generarse este tipo de cambios a nivel social y de divulgación de información, los espacios académicos también buscan desarrollar nuevas metodologías que inserten a los estudiantes en una nueva forma de concebir información, tanto para estar al día con los cambios, como para educar a través de los mismos. Manejar la información de manera responsable y utilizar los medios digitales como portales esenciales para el espectador. Meso, K. (2006), lo cataloga como: "programas que contemplan la enseñanza de la prensa para el nuevo entorno digital".

La reacción ante esta nueva sinergia en el mundo de la comunicación conlleva entonces a la creación de medios o canales digitales de información. Un ámbito explorado de forma empírica por muchos comunicadores ávidos de dar a conocer la información y posteriormente la inserción de los medios tradicionales al formato digital. Hoy en día la frecuencia de periódicos, blogs, radios y canales audiovisuales van tomando fuerza en una sociedad que necesita ver y percibir nuevas propuestas para adquirir información, los cuales van acompañados de las redes sociales, una nueva área de comunicación, la cual permite construir, gestionar y administrar la comunidad en línea, quienes lo manejan son denominados Community Managers.

"un Community Manager es aquella persona encargada/responsable de sostener, acrecentar y, en cierta forma, defender las relaciones de la empresa con sus clientes en el ámbito digital, gracias al conocimiento de las necesidades y planteamientos estratégicos de la organización y los intereses de los clientes. Conoce los objetivos y actúa en consecuencia para conseguirlos. Muy genéricamente podríamos decir que un Community Manager es aquella 
persona que preserva la identidad digital de la compañía”. (Ibáñez, M.D., 2014, p.25 en Asociación Española de Responsables de Comunidad)

Este manejo de redes sociales y calidad de imagen digital, se realiza no solo como una actividad de ocio, más bien desde los distintos usos que los medios digitales y el mundo de las redes sociales nos puede ofrecer para estar en vínculo con los públicos que a diario consumen todo tipo de información. Por ello tanto marcas, productos, personajes públicos y entre otras personas optan por contratar un Community Manager (CM) que se encargue de establecerlos en el mercado digital de la forma correcta, ejecutando tareas de marketing y comunicación visual para de esta forma enganchar a sus target objetivos. Ibáñez (2014), lo establece como: "la voz y los oídos de una marca en Internet" y cita a Connie Bensen quien señala que el Community "es la voz de la empresa puertas afuera y la voz del cliente puertas adentro".

Muchas organizaciones empiezan a darse cuenta de los beneficios que un CM puede reportarles en transparencia y comunicación empresarial, y a medio plazo también en ventas. Pero para ello debe tener el apoyo de la dirección, y la implicación del resto de personal. El CM no es un hombre solitario sino que se tiene que sentir apoyado por la organización, que ésta crea que su trabajo en los medios sociales le va a traer beneficios. No se trata de tener esa figura solamente para sentirse modernos. (Marquina, J. 2013, p. 27-28)

\section{Metodología}

El presente trabajo de investigación plantea un acercamiento a la situación laboral de los comunicadores sociales en la sociedad guayaquileña y el desarrollo del mismo desde sus diferentes orientaciones profesionales existentes. El artículo académico se realiza bajo dos tipos de enfoques: exploratorio y descriptivo, estos aportarán al enriquecimiento del tema antes mencionado. El enfoque exploratorio busca obtener una visión general de las áreas de estudio, logrando sistematizar y nutrir el tema, por otro lado, el enfoque descriptivo es mucho más definido, ya que detalla vínculos que relacionan a los fenómenos estudiados, en conjunto con las situaciones que se presentan. El proyecto investigativo tiene un enfoque cualitativo y cuantitativo debido al uso de métodos y técnicas relacionadas a esta metodología.

Al utilizar este enfoque cualitativo se pretende lograr profundidad en la obtención de información, donde destaquen las perspectivas de los entrevistados, cumpliendo con el objetivo principal que es examinar analíticamente los distintos puntos de vista de varios personajes inmiscuidos en la temática, los mismos que van desde directores de carrera de Comunicación Social de Guayaquil, hasta profesionales en comunicación como: periodistas de medios impresos, radio y televisión, relacionistas públicos, comunicadores organizacionales, periodistas digitales y community managers, quienes aportarán a la sustentación del análisis sobre la situación laboral y las perspectivas profesionales de las distintas áreas de comunicación existentes. Este enfoque permite dar a conocer los puntos de vista de los comunicadores sociales consultados sobre las temáticas presentadas, contrastando de esta manera la investigación en varios espacios de interpretación y análisis.

Se realizará la utilización del método exploratorio enfocado en la comunicación social y su aporte profesional en las distintas orientaciones o áreas de trabajo existentes con el fin de 
establecer el alcance que tiene en el manejo de masas y los diferentes públicos y entidades a los cuales brinda de forma indispensable su apoyo, dicho método colabora al desarrollo de la investigación de forma directa ya que sus características permiten conocer conceptos de la temática para posteriormente analizarlas desde diferentes opiniones de cada personaje representativo acorde al tema. De la misma manera; se busca analizar los espacios de trabajo existentes en comunicación en las empresas y medios de comunicación ecuatorianas con el objetivo de establecer un análisis comparativo entre todas las orientaciones: medios tradicionales, medios digitales, redes sociales, y entidades públicas y privadas, orientando el artículo académico de la profesión del comunicador social.

El enfoque cuantitativo se realizará por medio de la encuesta, un método que permitirá conocer cuáles son las perspectivas de los estudiantes de comunicación social en cuánto a la situación laboral y las ofertas que se encuentran en el mercado actualmente, se mostrará el porcentaje de estudiantes que se encuentren trabajando, tanto en comunicación u otra ocupación, los alumnos encuestados pertenecen a séptimo y octavo semestre del horario nocturno en la Universidad Politécnica Salesiana.

\section{Resultados}

Los resultados del presente artículo académico son tomados con base a la información recogida de profesionales en comunicación social que ejercen desde las diferentes ramas u orientaciones existentes, como: el periodismo en los medios tradicionales de prensa, radio y televisión, relaciones públicas, comunicación institucional u organizacional, periodismo digital, y el manejo de comunidades internautas o community management, además del punto de vista de representantes de algunas facultades de Comunicación Social en la ciudad de Guayaquil, mediante entrevistas a profundidad, investigación y realización de encuestas, con lo cual se facilita la obtención de los datos y opiniones presentados a continuación.

En los últimos años la profesión del comunicador social en Guayaquil ha traspasado distintos cambios a nivel, político, social, económico y tecnológico, tales cambios han repercutido de forma inminente en el carácter profesional del comunicador social, quien se ha tenido que adaptar de forma abrupta desde las políticas propuestas por el actual gobierno, hasta la inserción de los medios digitales, generando variaciones en la estrategia de trabajo que cumplen los profesionales en comunicación social desde las distintas orientaciones existentes. Cabe recalcar que en materia de comunicación es el mismo estudiante quien se inclina por la rama o área que quiere ejercer en su profesión, pero que en resumidas cuentas trabaja como comunicador desde los diferentes espacios que elije actuar.

Para Juan Manuel Yépez (2016), Editor General de Diario EXTRA ${ }^{1}$, el comunicador social de hoy, se convierte en verdadero gestor de las distintas actividades propuestas desde la academia, lugar donde en ciertas facultades de comunicación social de Guayaquil, el estudiante escoge hacia qué rama o área profesional quiere especializarse, Yépez considera al periodismo como un estilo de vida en donde, sea cual sea el medio de transmisión: radio, blogs, redes sociales o páginas webs; el objetivo de informar a la comunidad es el mismo, con la única variable de concebir y administrar la información desde las diferentes plataformas existentes,

\footnotetext{
${ }^{1}$ Diario EXTRA: medio de comunicación impreso.
} 
tratando siempre de sorprender al público con distintos contenidos y experiencias tomadas de los espectadores para elaborar una nota periodística.

En el caso del periodismo argumenta Yépez, desde el 2013 se vive una situación caótica gracias a los estamentos gubernamentales establecidos bajo la tutela de la Superintendencia de la Información y Comunicación ${ }^{2}$, generando cambios consecuentes, e interviniendo en las universidades para de alguna manera politizar la comunicación, dejando como resultado estudiantes confundidos sobre la profesión periodística, en donde se otorga la creencia de que una Ley de Comunicación debe ser un esquema al que debe apegarse el alumno, o lo que es peor aún, asegura, se estaría formando "estudiantes que no se van a salir de la cancha armada por el gobierno lo cual es un error absoluto". Sin embargo desde los medios de comunicación los requerimientos que ésta ley pide son aceptados, como por ejemplo: el derecho a la réplica y el derecho a la rectificación, presentes en los artículos 24 y 23 de la Ley Orgánica de Comunicación (LOC).

Con base a la situación laboral del periodista, Juan Manuel Yépez (2016), primero hace una dura crítica al sistema educativo, alegando la gran responsabilidad que debería tener la academia de adaptar a las nuevas generaciones, no solo en la práctica de una pasantía temporal, que al final se maneja como una obligación para el estudiante, quien no se empapa debidamente de la realidad que se mueve en el medio de comunicación y que consecuentemente se refleja en el espacio mediático al cual espera llegar sin éxito, producto de la falta de preparación académica y personal. Yépez asegura que muchas veces no es cuestión del título, "la experiencia y el perfil profesional se va puliendo poco a poco, según el nivel de interés que el mismo periodista o estudiante de periodismo quiere forjar", o en el último de los casos, comenta el director de diario EXTRA, esta poca demanda de periodistas es consecuencia del miedo a la actual ley, llamada "mordaza" que tienen los nuevos profesionales de comunicación.

Andrés Jungbluth (2016), periodista televisivo de Ecuavisa y locutor de Radio Centro, desde su perspectiva hace alusión a la gran diferencia que se ha generado en la carrera profesional de los periodistas respecto a otros años, el hecho que marca el ejercicio de la profesión, como un sector de oposición, una visualización generada por el gobierno y que de cierto modo no permite la total fluidez en el trabajo que se pretende entregar al público. Jungbluth, menciona además que la labor periodística está expuesta a un marco regulatorio en donde cada una de las coberturas, las imágenes, las entrevistas, los lugares hasta donde llegan y la información que se quiere difundir está en constante monitoreo por parte de este campo de acción que regula la ley de comunicación, provocando que el oficio no transcurra por su naturaleza y dejando parte a un juzgador que cuestiona permanentemente el trabajo que se emite.

“Los medios de comunicación, las empresas de comunicación, han sentido los efectos de un comportamiento en el mercado publicitario complicado, y eso ha llevado a que las plazas de trabajo se reduzcan, en cuanto a la opción de ingresar a un medio de comunicación. Cada vez son más los alumnos que se gradúan y no mucho los medios que crecen para presentarlo". Menciona Jungbluth, A. (2016) quien en base a esta problemática también reconoce que para el

\footnotetext{
${ }^{2}$ Superintendencia de la Información y Comunicación: organismo técnico de vigilancia, auditoría, intervención y control en el ámbito administrativo del ejercicio de los derechos a la comunicación, establecidos constitucionalmente.
} 
comunicador social existen otros campos de la comunicación en los que se puede navegar. Los escenarios de trabajo avanzan hacia muchas otras áreas como la publicidad, las relaciones públicas, como el contenido de comunicación organizacional, la comunicación a través de redes, "en fin es mucho más amplio el campo del comunicador social versus el del periodista, aun cuando el periodista también tiene que tener esa amplitud", Jungbluth (2016) adicionalmente considera que el oficio del periodista debe estar marcado de nuevas ideas, de identidad y de ejercer de forma recursiva la comunicación por medio de la tecnología.

César Eduarte Gavilánez (2016) periodista de Ecuador Tv, cadena de televisión de servicio público vigente desde octubre del 2007 como oferta en la campaña electoral del Econ. Rafael Correa, comenta su punto de vista con base al tema central de este artículo, y menciona la evolución tecnológica como referente importante para los nuevos hacedores de la comunicación, jóvenes que se interesan por aprender o colaborar con información, generadores de contenidos relevantes realizados por medio de sus Smartphone, en donde elaboran materiales noticiosos por medio de imágenes o videos que con el fin de dar a conocer la verdad se convierten en "reporteros ciudadanos". Esta actividad según indica Eduarte (2016) impulsa a la profesionalización o incursión de la comunicación social por medio de la práctica y estudio de esta carrera.

Para Eduarte (2016) un verdadero comunicador social, debe tener la vocación, la personalidad y la necesidad de comunicar algo y transformarlo en algo positivo, un mensaje que permita a la sociedad manifestarse a través de una información. Además comenta que el desarrollo de un periodista debe ser constante, la preparación debe ser referida como algo continuo para de esta forma exponer un punto de vista, experiencia y el modo de comunicar mejor a la sociedad. En cuanto a la Ley Orgánica de Comunicación, Eduarte (2016) comenta que esta ley ha mejorado el quehacer periodístico de los actuales comunicadores, y desaprueba que se la considere como una "ley mordaza", pues explica que en Ecuador no ha existido ninguna sanción, exilio o encarcelación hacia un periodista que haya dicho algo en contra de alguien. El periodista menciona la importancia de esta ley como defensora de los derechos del comunicador para ejercer su trabajo, menciona que la LOC, "facilita las herramientas deontológicas con las cuales puede generar una mejor cobertura, se puede obtener mejor información de sus fuentes, y la obligación de contrastar la información que es algo que va mucho más allá de una ley”.

Eduarte (2016) también hace alusión a la seguridad que genera la ley de comunicación al ser el periodista quien ejerce esta profesión de forma responsable, evitando que este caiga en un linchamiento mediático; gracias a la ley, la cual la considera una "herramienta que permite manejar de forma correcta la información”, estimula a tratar el tema de la responsabilidad ulterior algo de mucha importancia entre el medio y la sociedad. El periodista de Ecuador Tv, defiende el trabajo que realiza este medio público, y denota la situación de polaridad que existe en el país desde hace 15 años, cuando no existía este medio de comunicación y los medios comunitarios eran escasos; tiempos en los que la única información que se obtenía directamente era del medio privado, un espacio manejado por las empresas privadas que tratan la comunicación, o que tratan contenidos, dependiendo de las circunstancias en que les convenía.

"A diferencia de los medios privados, que en realidad tienen su forma interna de manejar su comunicación, de cómo manejar sus agendas diarias, de cómo priorizar las noticias”, Eduarte 
(2016), destaca que el medio público, se respalda en la ley de comunicación siguiendo paso a paso todos sus principios, preceptos y artículos, puesto que esta ley ha permitido dignificar el trabajo del periodista, quien en el pasado obtenía sueldos muy bajos por la falta de experiencia en el campo, lo que revelaba la precarización en el ámbito laboral del cual el también formó parte. Con la actual ley se normalizó el marco laboral de los comunicadores, se les otorgó mejores herramientas, mejor ambiente laboral y a la vez mejores remuneraciones. A pesar de esto, Eduarte (2016) toma en cuenta que en Ecuador, no hay mercado todavía importante para la avalancha de comunicadores nuevos que están todos los años entregando a la sociedad, considera que las empresas no dan las facilidades, ni la oportunidad para que los nuevos profesionales demuestren sus capacidades, pues la traba más frecuente es la falta de experiencia en el medio.

Sin embargo en comunicación existen otras ramas o áreas de desenvolvimiento para el profesional, tal es el caso de las relaciones públicas, un campo comunicacional que ha generado un crecimiento notable tanto a nivel académico como en el mercado laboral, ya sea en empresas públicas y privadas como agencias start up que buscan dar a conocer por medio de las distintas estrategias de comunicación, la marca, persona o producto hacia un público clave.

Martha Pine Andrade (2016) relacionista pública en Axis Comunicaciones y dueña de la agencia de relaciones públicas MAPA, menciona que el rol del comunicador social es elemental en este campo profesional, pues por medio de sus aptitudes competentes puede desempeñarse de manera eficiente, considera más que importante la formación académica y experimental en el campo profesional ya sea en medios de comunicación o alguna empresa en la cual puede emplear habilidades comunicacionales. Pine, M. (2016) señala que el tipo de experiencia que se adquiere por medio de una práctica profesional es fundamental para definir hacia qué rama de comunicación dirigirse, periodismo, comunicación organizacional o relaciones públicas.

Pine, menciona que el campo ocupacional del relacionista público en Guayaquil actualmente es competitivo, incluso recalca el trabajo de empresas star up, dedicadas a relaciones públicas, agencias mediáticas que tienen la oportunidad de emprender y crecer a nivel profesional, "una oportunidad de palestra única" que incide en algunas agencias como: 'La Nueva Agencia' y 'Dimitrakis'. Sin embargo, este campo comunicacional no puede ser ejecutado por cualquier persona, advierte Pine, se requiere de experiencia, credibilidad, pensamiento estratégico, poder de convocatoria, entre otras aptitudes importantes que se toman en cuenta y que generan grandes resultados en cualquier empresa o entidad pública/privada.

Karen Rosero (2016) Licenciada en Ciencias de la Comunicación y relacionista pública de Norlop desde su experiencia en ONGs, empresas privadas, y el manejo de distintas cuentas manifiesta la labor que se ejecuta desde los distintos escenarios para los cuales ha generado resultados a través de la comunicación, resalta el papel del comunicador social en este amplio espectro de la profesión y la versatilidad que se puede llegar a obtener en el tema de las relaciones públicas, un mercado laboral que permite crear vínculos sociales y en donde todos forman parte importante de esta ocupación, incluyendo periodistas, medios de comunicación, entidades públicas y privadas, etc.

Para Rosero (2016) el campo de las relaciones públicas se ha diversificado y aumentado mucho en los últimos tiempos en el Ecuador, tomando la relevancia que esta profesión significa, 
tanto para los relacionistas públicos como para las empresas que deciden contratarlos, pues se considera a las relaciones públicas como un área que permite generar contenidos, noticias y manejar temas coyunturales de forma correcta, factores importantes que toman en consideración las empresas públicas y privadas por su efectividad y el manejo de estrategias de comunicación, vital para generar una noticia apropiada para el medio, es decir contenidos de calidad prestos para su publicación según la marca, producto, empresa o persona a la cual se preste la asesoría pertinente.

En el marco laboral, Rosero (2016) considera que en los últimos años sí ha existido un incremento en esta área de la comunicación en lugares como Quito y Guayaquil, debido a la cantidad de marcas que se han volcado por el uso de las relaciones públicas para crear noticias, a través del free press, una publicación que no es pagada y que se gestiona dentro del relacionamiento con el medio de comunicación. Este tipo de publicación resulta ser más creíble ante el público y se lo encuentra en anuncios, prensa escrita, televisión y radio. Es destacable la labor comunicacional que realiza el relacionista público desde esta profesión, lo cual conlleva a una constante preparación y enfoque de lo que sucede a su alrededor con la coyuntura, las noticias nacionales, locales, internacionales e incluso el trabajo de la competencia para poder mejorar. El relacionista público debe tener excelentes vínculos en todo nivel y estar presto a servir, ser claro y transparente para que su campaña tenga éxito.

María Belén Castro (2016) periodista que actualmente labora en el Servicio Nacional de Aduanas del Ecuador, comenta el trabajo que se realiza desde la comunicación organizacional, un campo que según la periodista, se ha desarrollado generando competencia en el mercado laboral. Esta rama de la comunicación, se ha gestionado de tal forma que es el comunicador quien se encarga de armar las notificaciones que se generan dentro de una empresa o institución para que de esta forma sus empleados o funcionarios estén motivados a seguir los objetivos planteados dentro de su espacio de trabajo, esta labor se realiza a través de campañas comunicacionales y de vinculación con la sociedad, los cuales requieren de un arduo trabajo realizado por un departamento de comunicación que se encarga de las relaciones públicas, la publicidad y la prensa requerida a la hora de informar a los medios de comunicación.

Para Castro, M. (2016) un comunicador organizacional debe poseer habilidades esenciales al momento de llevar a cabo su gestión, estas habilidades tales como el pensamiento analítico, el cual permite generar campañas comunicacionales y actuar ante una crisis o impacto mediático no deseado, ayudan a sobrellevar el trabajo del comunicador ante la imagen de la empresa, menciona la importancia de manejar contenidos multimedia por medio de textos o noticias, imágenes y videos en donde se muestre la labor que ejecuta la empresa. Castro (2016), considera que el periodista es la persona ideal para ocupar este espacio, debido a la experiencia de trabajo bajo presión, el manejo de agenda, la redacción, el don de gente y el conocimiento de cómo se mueve el medio, aptitudes que ha obtenido gracias a su paso por medios tradicionales, medios digitales y community manager, los cuales han forjado una transición muy importante en su carrera, posicionándola en un área donde completa sus conocimientos con relaciones publicas y comunicación corporativa.

Dentro de una dirección de comunicación, tiene que haber personas encargadas para distintas cosas, como: el manejo de conceptos para las campañas comunicacionales 
(comunicador corporativo), el contenido hacia redes sociales (community manager), la publicación que se genera para los medios de comunicación (relacionista público) y un diseñador gráfico que se encargue de producir y editar contenidos digitales, todos enfocados en un mismo objetivo de crear un impacto positivo a través de la comunicación y la fluidez entre líderes y equipos de trabajo dentro de una empresa o institución.

Para Verónica Arosemena (2016) Consultora de Comunicación y Periodista, el trabajo de comunicación corporativa permite que las relaciones internas de una empresa o institución fluyan de forma adecuada, asesorando los distintos espacios y relaciones entre empleados - jefe y viceversa, gestiona la comunicación entre distintas áreas, incluida la de Recursos Humanos, y analiza la dinámica existente dentro de la compañía para que las personas se sientan realmente a gusto con el lugar en que laboran, plenamente informados y de forma oportuna. Arosemena (2016) considera que Ecuador apenas se está poniendo al día en materia de comunicación organizacional, debido a que en el pasado, casi ninguna empresa tenía un departamento completo y equipado de comunicación, comenta además que desde sus 5 años de experiencia y trabajo en asesoría a distintas empresas, éstas luego de un diagnóstico en comunicación interna, acceden a contratar por lo menos a una persona que esté especializada en la materia, y por consiguiente brinde soporte a los departamentos de Recursos Humanos, un área muy alejada de la Comunicación Organizacional y que erróneamente se dedicaba al manejo de la comunicación interna.

Arosemena (2016), fortalece el argumento de que la Comunicación Organizacional es una herramienta estratégica para la compañía, empresa o institución en la que se trabaje, ésta puede ser dirigida y gestionada por alguien que tenga una experiencia en Comunicación Interna, o que se haya preparado para esta área de la comunicación, considera al comunicador como alguien que actualmente no puede limitarse a desarrollar solamente una habilidad específica en cuanto a la comunicación, más bien tiene que tener varias herramientas de trabajo, "como una mochila mejor equipada" para poder responder a las diferentes situaciones que se le presentan en el mundo laboral. El comunicador debe ser alguien proactivo, capaz de generar nuevas propuestas sobre qué y cómo comunicar hacia su público interno, en el caso de la comunicación corporativa, ser audaz y utilizar sus conocimientos de redacción de forma atractiva; expresarse mejor, es sinónimo de crear mejores vínculos entre los líderes y el resto de la compañía, de esta forma se puede convencer a la entidad de invertir en esta área, con un objetivo claro del cual todos son parte.

Con el despliegue de la tecnología son muchas las oportunidades que desembocan a los nuevos comunicadores sociales, quienes por vocación y deber en comunicar abren espacios digitales para poder dar a conocer desde distintos escenarios información de todo tipo. De la misma forma tanto comunicadores, ciudadanos comunes y medios de comunicación están inmersos en esta oleada de red de redes para estar más cerca de la información y de forma inmediata. En Ecuador, según el monitoreo realizado por la CIESPAL ${ }^{3}$, bajo la tutela de José Rivera Costales, hasta el 2012 eran 34 los medios digitales existentes en la plataforma, el portal web Fundamedios, en un estudio más actualizado del 2015, acentuaba 60, los cuales la mayor parte pertenecían a la capital ecuatoriana, Quito, y solo 14 de ellos pertenecientes a Guayaquil.

\footnotetext{
${ }^{3}$ CIESPAL: Centro Internacional de Estudios Superiores de Comunicación para América Latina
} 
Juan José Palacios (2016), periodista deportivo del medio digital Studio Fútbol, en sus cuatro años de experiencia en este medio, valora el desarrollo que ha tenido este campo comunicacional que cada vez toma más fuerza en nuestro país. Los medios digitales en conjunto con las redes sociales han generado cambios significativos en la comunicación, pues antes el medio habitaba de forma unidireccional en cuanto a la información, pero con el uso de los medios digitales el usuario se convierte en un generador de noticias, o "reportero ciudadano" del cual algunos medios toman referencia o fuente para la realización de un mejor contenido local o internacional. A pesar de que las redes sociales sean vistas como un arma de doble filo en el flujo de la información, es el profesional quien debe hacerse cargo de la verificación e investigación correspondiente, tener las bases planteadas con respecto a los conceptos que otorga la academia y mantener al periodismo tradicional como mayor ejemplo para el ejercicio.

En el caso particular de Studio Futbol, comenta Palacios (2016) el crecimiento de esta plataforma desde el 2012, año de su ingreso al medio, el conjunto de seguidores ha aumentado de manera considerable; pasó de 8000 seguidores a los casi 190.000, cantidad que se ha generado gracias al uso de redes sociales, específicamente Twitter, una red social antes considerada para el microblogging ${ }^{4}$ personal, pero que empezó a tomar relevancia tanto para los medios digitales como tradicionales, para el envío de información instantánea; otras redes sociales como Facebook e Instagram se fueron sumando con el paso del tiempo siendo estas herramientas bastante interesantes, capaces de evolucionar contenido de manera constante, en donde se visualizan tipos de material escrito y audiovisual, tendencias tecnológicas para la cual, considera Palacios (2016) es importante el manejo de distintas herramientas como: hootsuite, Photoshop, illustrator, audition, infogram, entre otras, muy necesarias para la producción de contenido digital.

Palacios, J. (2016) considera que en Ecuador el desarrollo de los medios digitales ha sido considerable, tomando en cuenta que estos generan ingresos por medio de la publicidad, y a su vez esta se consigue en favor de la cantidad de visitas que el medio digital como tal obtiene. El crecimiento virtual se promulga de manera que cualquier comunicador, sin necesidad de pertenecer a un medio puede crear sus propias plataformas web para dar a conocer sus contenidos, la clave principalmente para estos nuevos emprendedores, según Palacios, es tener un perfil dinámico en la cual se obtenga la mayor facilidad de crear a través de las innumerables herramientas y aplicaciones para el desarrollo de reportajes, especiales, multimedia, videodocumentales, entre muchas otras opciones que el comunicador social realiza en el campo digital, un trabajo que exige saber sobre conceptos de publicidad, de marketing, de medios, etc. El periodista digital, gracias a su versatilidad ocupacional termina convirtiéndose en un community manager capaz de manejar los medios necesarios para la difusión de la información y el vínculo con la audiencia.

Danna Hanna Avendaño (2016), periodista dueña de su propia productora de marketing digital y locutora del programa Influencers, en el medio online Pixel Radio, comenta su experiencia en el medio como un sistema de emprendimiento que muchos comunicadores con preparación pueden optar en el campo laboral, el marketing digital le ha permitido al principio trabajar de forma empírica con la promoción de distintas marcas, para las cuales a favor de su

\footnotetext{
${ }^{4}$ Microblogging: es un servicio que permite a sus usuarios enviar y publicar mensajes breves, generalmente solo de texto.
} 
experiencia en medios de prensa, radio y televisión, ha logrado direccionar hacia qué público puede apuntar; además de la utilización de sus redes sociales, aprovecha el espacio de radio para la difusión de marcas, personas, músicos, emprendedores, entre otros. Para Hanna (2016) el tema de la estrategia es muy importante, lo ha canalizado desde sus horario de emisión radial hasta en el estudio de cómo y cuándo puede publicar contenido en sus redes y que esta funcione.

La labor de periodismo, community manager y dirección de Influencers, ha desarrollado en Hanna, la capacidad de poder trabajar con cualquier estrato social, tendencia política o suceso, situaciones que todo comunicador debe ampliar, pues actualmente considera Hanna, D. (2016) es muy complicado encontrar profesionales de radio, que hayan trabajado en producción de televisión y sepan qué funciona o no en el tema del rating. Argumenta además que el público de Internet no es el mismo de la televisión y que es muy difícil que estos logren fusionarse.

Conquistar Internet es un desafío que aleja a esta periodista de volver a los medios tradicionales, generar algo propio fue el objetivo que se desarrolló incluso antes de abril del 2016 cuando emitió el primer programa de Influencers, el tema del "branding personal" 5 se ha manejado desde mucho antes y es esencial para dar a conocer el trabajo en el medio digital. Una manera recomendada según Hanna, D. (2016), es aportando con contenido, en su caso, el mundo del entretenimiento. Buscar un factor que caracterice al comunicador con sus aportes positivos, emprendimientos, cultura, entre otras muchas opciones que van formando al comunicador, como una marca posicionada en el medio gracias a lo que pueda transmitir y emitir a la gente en redes sociales.

Gabriela Pinasco (2016) periodista y community manager del canal Ecuavisa, en su labor digital como redactora de contenidos noticiosos para este medio, comenta sobre la relevancia que tienen actualmente los medios digitales y redes sociales, un fenómeno que ha generado un gran impacto social al convertirse en un sistema totalmente bidireccional, en donde el internauta en ciertas ocasiones complementa una noticia desde su experiencia o material audiovisual. Para Pinasco (2016) el manejo de redes sociales en medios de comunicación, resulta ser el método ideal para comunicar de forma más acelerada y extensa, pues considera que los formatos estáticos como la radio, la prensa y la televisión no pueden ampliarse más allá de la información que ofrecen al momento de su publicación, lo que es distinto en medios digitales en donde puedes ir más allá de la información que lees o visualizas con solo hacer un clic.

Aunque la ocupación de community manager no esté contemplada como una materia en las universidades de nuestro país, comenta Pinasco, G. (2016), los cursos y talleres que se ofrecen de esta rama comunicativa ayudan a desenvolver de manera empírica esta ocupación, que si bien se maneja de forma responsable, quienes la practican deben tener habilidades destacadas del periodismo como la redacción, el contraste de la noticia, e incluso la obtención de fuentes propias para tener noción directa de lo que está sucediendo a través de un monitoreo constante que se desarrolla en el caso de las social media de un canal de televisión nacional. La información que se maneja en Ecuavisa como medio tradicional, es la misma que se desarrollan

\footnotetext{
${ }^{5}$ Branding personal: La marca personal, en inglés Personal Branding, es un concepto de desarrollo personal consistente en considerar a determinadas personas como una marca, que al igual que las marcas comerciales, debe ser elaborada, transmitida y protegida, con ánimo de diferenciarse y conseguir mayor éxito en las relaciones sociales y profesionales.
} 
en las redes sociales y medios digitales correspondientes, con la diferencia que por medio de sus redes sociales el community manager se encarga del seguimiento o real time de la información de acontecimientos relevantes que transcurren a nivel nacional o internacional.

En la ciudad de Guayaquil (Ecuador), se consume menos televisión de lo que probablemente se hace en otras ciudades asegura Pinasco (2016), las redes sociales se encuentran en todos lados y es el método más efectivo para poder comunicar, defiende este argumento al sostener que en la ciudad aproximadamente un $68 \%$ de las personas mantienen activas cuentas de Facebook, un $12 \%$ lo hacen en Twitter y solo un $8 \%$ en Instagram. Considera que la inversión en plataformas digitales y redes sociales son esenciales actualmente pues no son el futuro, sino el hoy para muchas empresas que buscan una retroalimentación de su trabajo.

Este artículo académico busca responder cual es el papel que toman las facultades de Comunicación Social de Guayaquil ante el nivel de preparación, vinculación con la sociedad y el enfoque que tienen de esta carrera y las áreas en las que se puede direccionar el futuro profesional. Abrimos paso a la indagación de las propuestas ocupacionales que ofrecen algunas universidades públicas y privadas en cuanto a comunicación como: la Universidad de Guayaquil, la Universidad Laica Vicente Rocafuerte, la Universidad Católica Santiago de Guayaquil y la Universidad Politécnica Salesiana.

Julio César Armanza, director de Carrera de Comunicación Social de la FACSO, Universidad de Guayaquil, establece el panorama que esta entidad pública vive actualmente, como primera instancia la Facultad de Comunicación Social recién en el 2017 incorpora a la primera promoción de estudiantes que hayan cursado 8 semestres, se busca rediseñar y aprobar la carrera de periodismo, exclusivamente para estudiantes que solo deseen establecerse en medios tradicionales, se ha implementado docentes con experiencia en el manejo de redes, gracias al nuevo campo laboral existente en Ecuador, referente al manejo y tráfico de las redes sociales y medios digitales. En cuanto al tema de vinculación con la sociedad por medio de la Ley Orgánica de Comunicación, se establece que el vínculo social se debe realizar por medio de proyectos que ayuden a las comunidades a expresarse a través de medios de comunicación, anteriormente se debían hacer bajo el programa del Buen Vivir, en la colaboración de escuela o asilos existentes en comunidades situadas en la provincia del Guayas y Santa Elena.

Armanza, J. (2016), reconoce la situación del mercado laboral para los comunicadores desde distintos preceptos no tan favorables, como el hecho de que hasta el momento no es el mejor campo de empleo debido a la saturación que existe en las pocas plazas de trabajo en las cuales han existido recortes de personal, no existen nuevas posibilidades en otros espacios en donde probablemente la causa sea la circunstancia política y económica que viven los medios de comunicación y finalmente la competencia de un entorno que cambia rápidamente y en donde no se avizora mayor inversión debido a las disposiciones legales. Sin embargo la propuesta académica de 54 materias que oferta esta facultad, promete formar estudiantes aptos para desplegarse en el mercado laboral ya sea en medios de radio, prensa, televisión y digital.

Efraín Luna Mejía (2016) Director de la Carrera de Comunicación en la Universidad Católica de Santiago de Guayaquil, comenta el panorama de esta institución al ofertar la Carrera de Comunicación Social con dos menciones: Periodismo y Literatura, situación que para el 2017 
se transformará en 2 carreras distintas, en donde según asegura Luna E. (2016), este cambio permitirá ampliar las posibilidades de oferta con la gente que quiere hacer comunicación desde el área periodística, audiovisual, estratégica, publicitaria, organizacional, entre otras. Un cambio que se dispone a favor de la norma CINE (Clasificación Internacional Normalizada de la Educación ${ }^{6}$ ) de la ONU, en donde se solicita que en comunicación no puede estar inmerso el periodismo, pues este campo se convierte en una nueva carrera, o rama de comunicación. Hasta el momento las menciones existentes permiten desarrollar un perfil en donde el profesional se pueda desempeñar en áreas de periodismo como prensa, radio, televisión y medios digitales, mientras que en literatura tienen la posibilidad de ser gestores de eventos culturales, guionistas, libretistas, escritores de libros e incluso profesores de literatura.

Luna E. (2016) asegura que en el tema del mercado laboral sus estudiantes empiezan a trabajar incluso antes de culminar la carrera, y que por lo menos alrededor del $70 \%$ de los estudiantes están en el área que ellos han optado, esto a pesar de las dificultades que enfrenta el sector empleo debido a la situación política del país, por lo cual los jóvenes esparcen sus posibilidades optando por otras alternativas vinculadas a comunicación, además de incursionar en los espacios que ofrece la tecnología en cuanto a los medios digitales, un panorama donde se empieza a generar procesos importantes.

Diana Almeida (2017), Coordinadora de la Carrera de Periodismo de la Universidad Laica Vicente Rocafuerte, comenta acerca del trabajo que se realiza desde esta facultad para la formación de nuevos profesionales en periodismo quienes desarrollan aptitudes en otras 3 ramas de la comunicación como: periodismo digital, comunicación corporativa y relaciones públicas.

Con alrededor de 30 años, la facultad de periodismo de la Laica, se ha destacado por tener en el mercado laboral excelentes profesionales en comunicación quienes según Almeida, D. (2017) podrían conformar aproximadamente un promedio del 50\%, dispersos en distintas áreas de la comunicación, desarrollando rangos importantes, como es el caso de Tania Tinoco, periodista de renombre quien forma parte importante de uno de los canales más antiguos del territorio ecuatoriano Ecuavisa. Al igual que el resto de facultades mencionadas anteriormente, para la Facultad de Periodismo el tema de la Ley de Comunicación significa una herramienta más de estudio para que los alumnos conozcan la realidad que se mueve en el medio y la sociedad, con el estudio también de otras leyes esenciales para el quehacer periodístico.

Katiuska Flores (2017) Directora de la Carrera de Comunicación Social en la Universidad Politécnica Salesiana, menciona los cambios que se realizan en la carrera con base a los reglamentos requeridos por el Consejo de Educación Superior ${ }^{7}$ (CES), en donde se elimina la anterior malla curricular que incluía la mención de Producción Audiovisual y Multimedial perteneciente hasta el periodo 49 del año 2016. Actualmente la Universidad Politécnica Salesiana en conjunto con las sedes de Quito y Cuenca, ofertan netamente la Carrera de Comunicación Social con el objetivo de una comunicación inclusiva que divide sus contenidos

\footnotetext{
${ }^{6}$ Clasificación Internacional Normalizada de la Educación (CINE): representa una clasificación de referencia que permite ordenar los programas educativos y sus respectivas certificaciones por niveles de educación y campos de estudio.

${ }^{7}$ Consejo de Educación Superior: organismo planificador, regulador y coordinador del Sistema Nacional de Educación Superior de la República del Ecuador.24\%16\%22\%38\%1. Áreas que pertenecen a la Comunicación Social Relaciones Públicas Comunicación Organizacional Community Manager Periodismo DigitalImagen1
} 
en narrativa sonora, multimedial, audiovisual y visual, la exigencia teórica epistemológica, acompañada de la práctica, es decir por cada hora de teoría se incluye una hora de práctica, metodología que se usará durante 9 semestres ( 5 años), antes se ofertaban solo 8.

Con base al mercado laboral y a la situación ocupacional de esta carrera obtuvimos los datos propiamente de los estudiantes de séptimo y octavo semestre nocturno, para conocer sus perspectivas laborales y a lo que aspiran en su carrera una vez terminados los periodos correspondientes.

Como primera instancia, se determinó el conocimiento que tienen los estudiantes en cuanto a las opciones de empleo que tienen en el mercado laboral, en una escala del 1 al 5, siendo este último (5) el de mayor rango y más importantes, ellos reconocieron que las siguientes áreas: Relaciones Públicas, Comunicación Organizacional, Community Manager y Periodismo Digital sí pertenecen a la Comunicación Social, en los siguientes porcentajes.

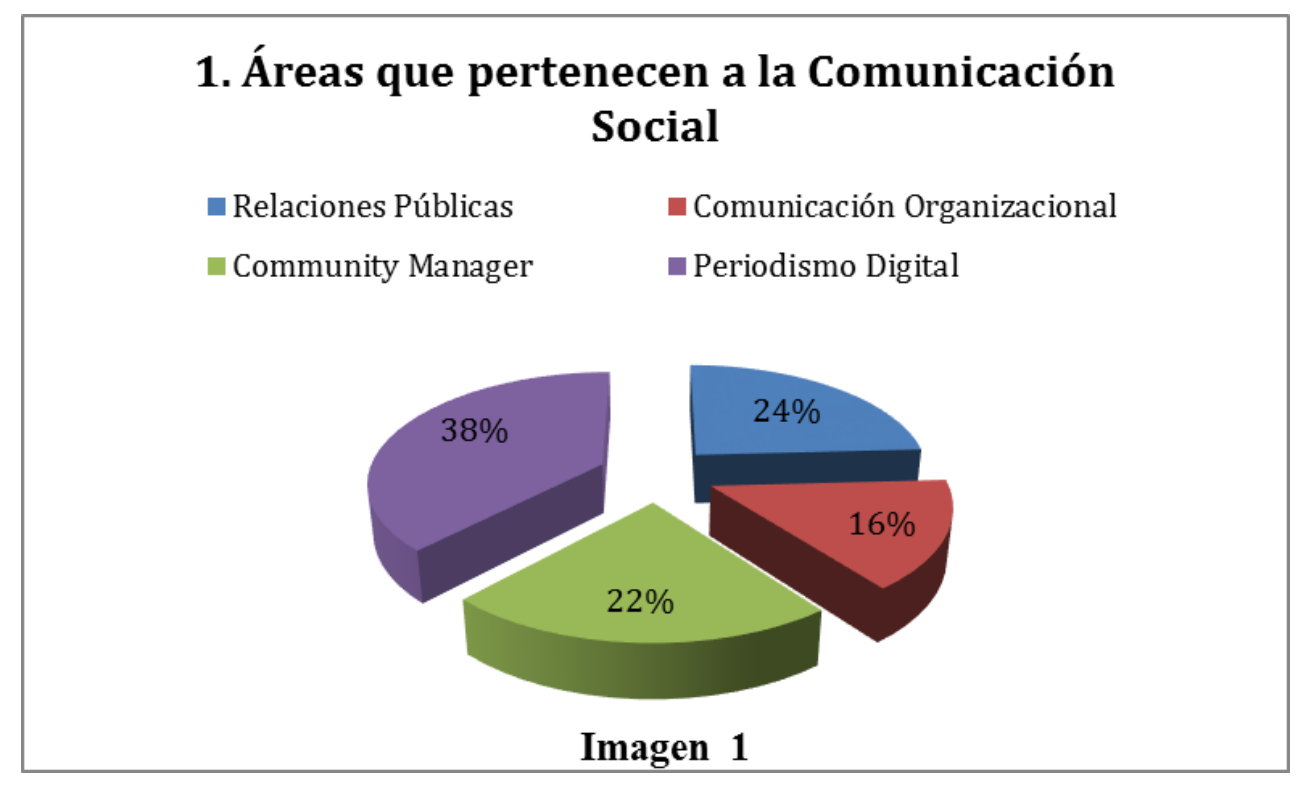

En la Imagen 1, el 24\% de los estudiantes reconocieron que las Relaciones Públicas, sí pertenece a un área de la Comunicación Social, el 16\% registraron a la Comunicación Organizacional, el 22\% optaron por Community Manager y el 38\% por el Periodismo Digital. 


\section{2. ¿Cuál de las siguientes áreas de comunicación estaría dispuesto a asumir según su experiencia?}

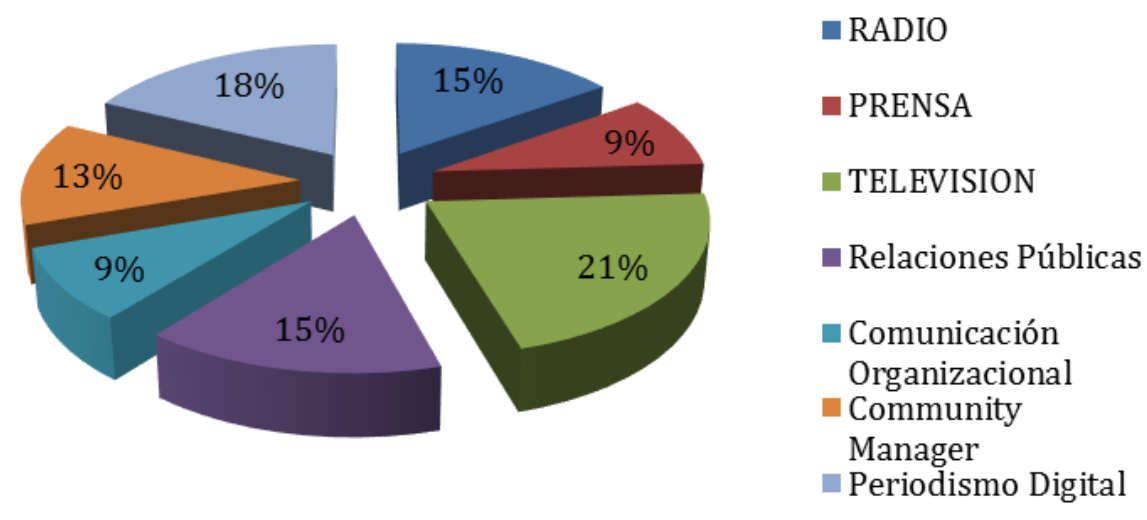

En la Imagen 2, se analiza cuáles son los retos profesionales a los cuales los estudiantes estarían dispuestos a asumir según su experiencia profesional en el caso que se les oferte un empleo, el 15\% optó por Radio, el $9 \%$ por Prensa, el $21 \%$ por Televisión, 15\% aspiran por Relaciones Públicas el $9 \%$ por Relaciones Públicas, el 13\% por Community Manager y finalmente el $18 \%$ de los estudiantes asumirían un cargo en el área de Periodismo Digital.

\section{3. ¿En cuál de las siguientes áreas de comunicación le gustaría desempeñarse en el mercado laboral?}

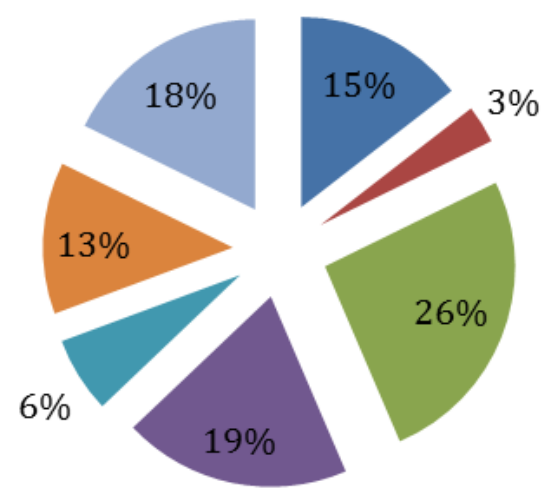

- Radio

- Prensa

- Televisión

- Relaciones Públicas

- Com. Organizacional

- Community Manager

a Periodismo Digital

En la Imagen 3, se analiza cuáles son las preferencias profesionales de los estudiantes en el mercado laboral, el 15\% optó por Radio, el 3\% por Prensa, el 26\% por Televisión, 19\% aspiran por Relaciones Públicas el 9\%, el 6\% por Comunicación Organizacional, 13\% por 
Community Manager y finalmente el $18 \%$ de los estudiantes les gustaría trabajar en Periodismo Digital.

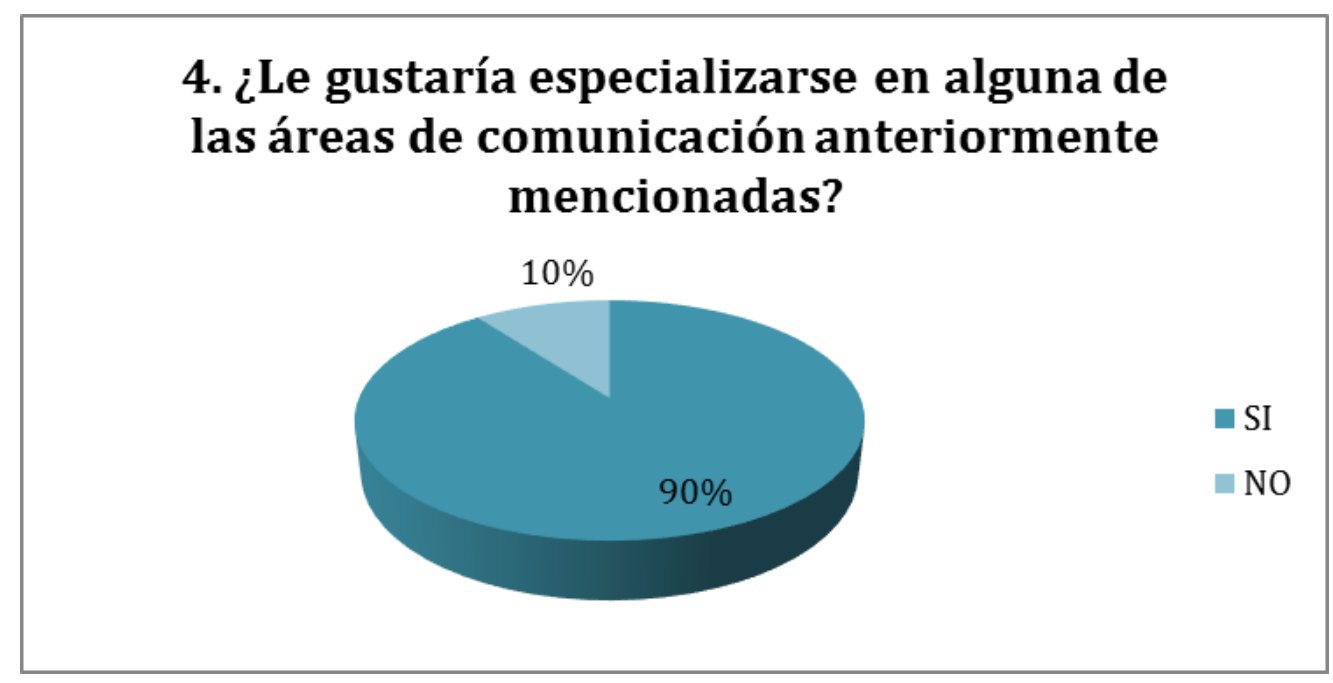

La Imagen 4, muestra el interés que poseen los estudiantes en cuanto a la especialización en alguna de las áreas de comunicación tales como: Relaciones Públicas, Comunicación Organizacional, Community Manager y Periodismo Digital. E1 90\% de ellos dijeron que SI les gustaría especializarse en alguna de ellas, y el 10\% optó por el NO.

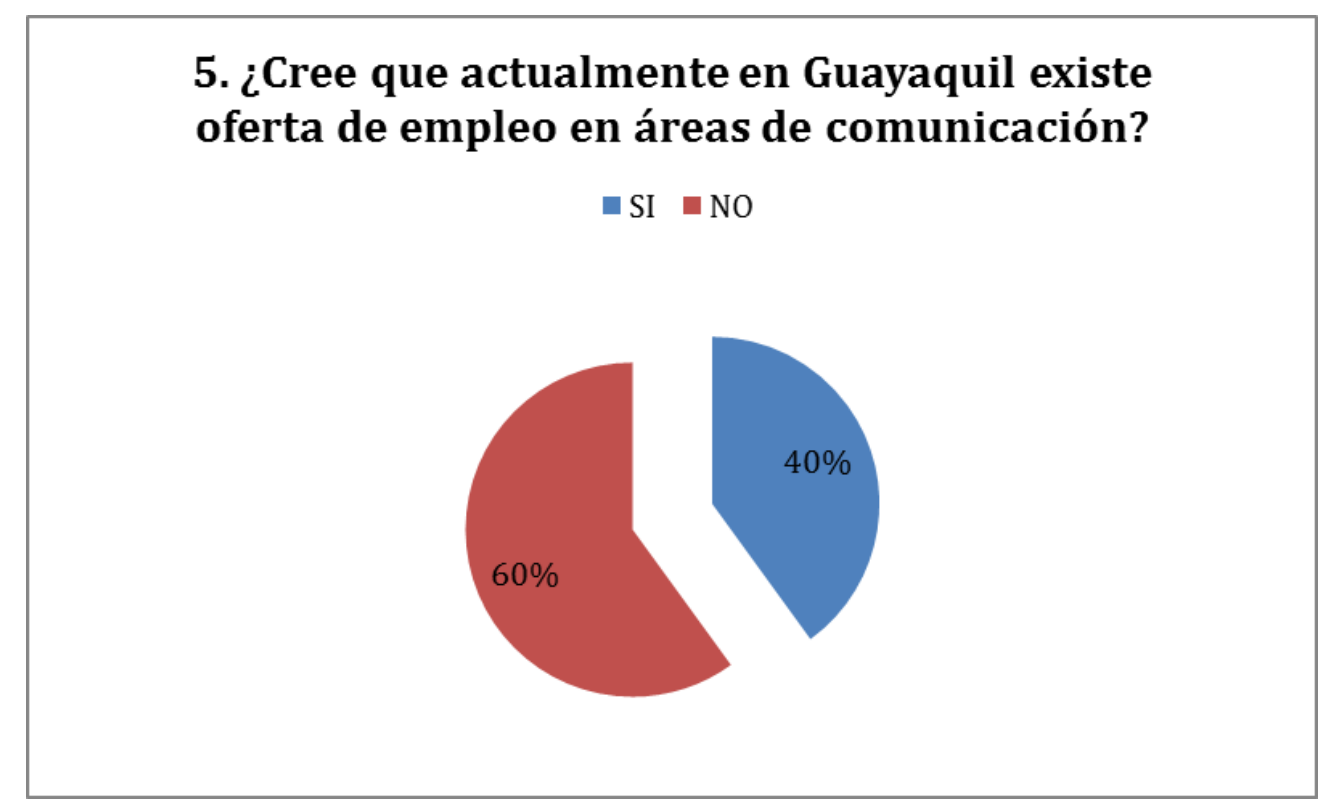

En la Imagen 5 se hace un sondeo en cuanto a la oferta de empleo en la ciudad de Guayaquil, el 40\% SI considera que existe oferta de empleo, mientras que el $60 \%$ opina que NO, ante esta respuesta se quiso saber cuáles consideran los estudiantes es la causa del problema, en la Imagen 6 se plasma lo siguiente, el 24\% opina que la causa se debe a la falta de experiencia de los nuevos licenciados, el 55\% opina que se debe a que el mercado laboral se encuentra saturado, 
el $17 \%$ piensa que se debe a la falta de compensación monetaria (salario) y el 4\% optó por la opción 'Otros'.
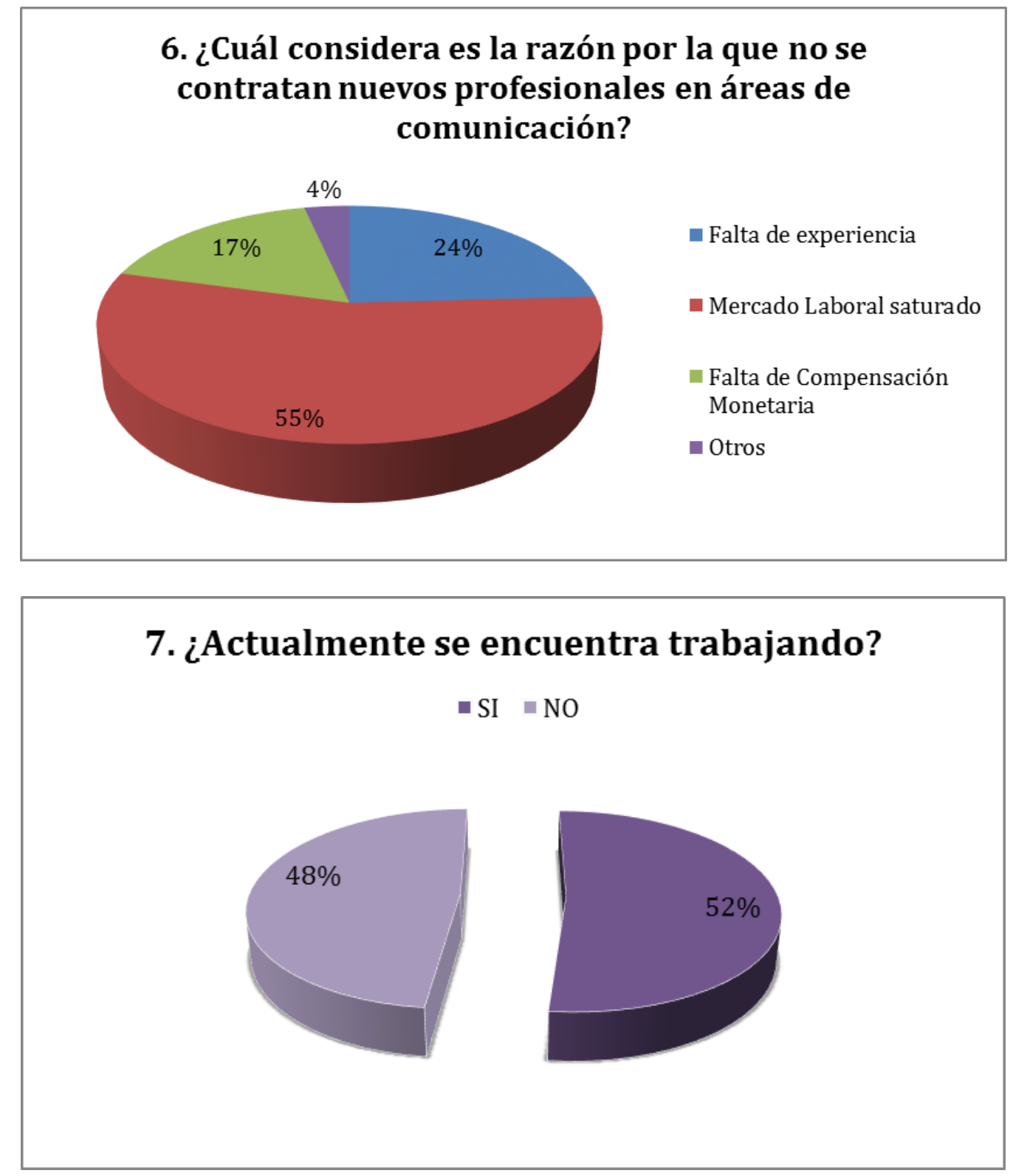

En esta última pregunta hicimos un sondeo de cuántos de los estudiantes del horario nocturno del $7 \mathrm{mo}$ y 8 vo semestre se encuentran actualmente trabajando, encontramos que el $48 \%$ SI lo está haciendo. Y el 52\% NO. Ante estas respuestas quisimos saber, en el caso de la respuesta afirmativa (SI) en qué área estos estudiantes laboran, ya sea en alguno de los campos ocupacionales antes mencionados o en otro no relacionado con la comunicación social. En la Imagen 8, se muestra que el 17\% de los estudiantes trabajan el Relaciones Públicas, el $11 \%$ en Community Manager, el 5\% en Radio, el 11\% en Televisión, el 6\% en Prensa escrita y el 50\% restante en otras áreas no vinculadas a la carrera que estudian. 


\section{8. ¿En qué área de comunicación se encuentra trabajando?}

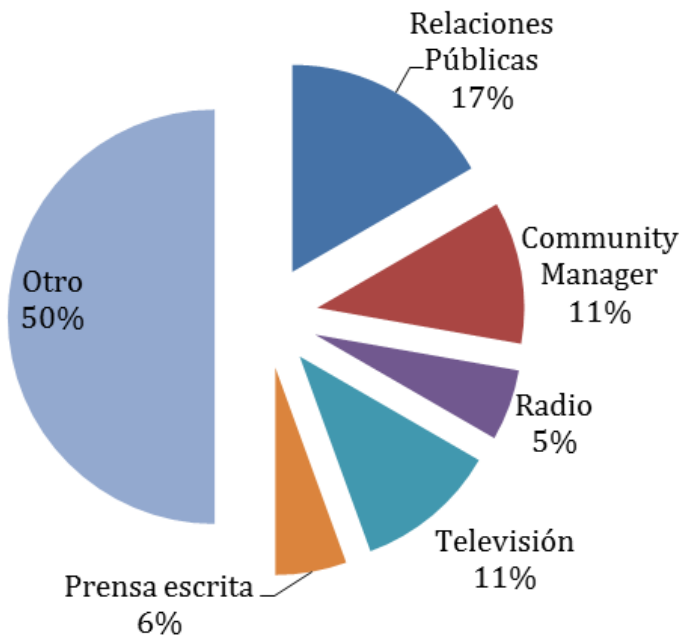

En el caso de la respuesta negativa (NO) que ocupa el 52\%, estudiantes mencionaron que no se encuentran actualmente activos en el campo laboral debido, a la falta de experiencia (28\%), falta de oferta laboral en comunicación (39\%), no han buscado en medios de comunicación $(28 \%)$, y por otras razones personales $(5 \%)$.

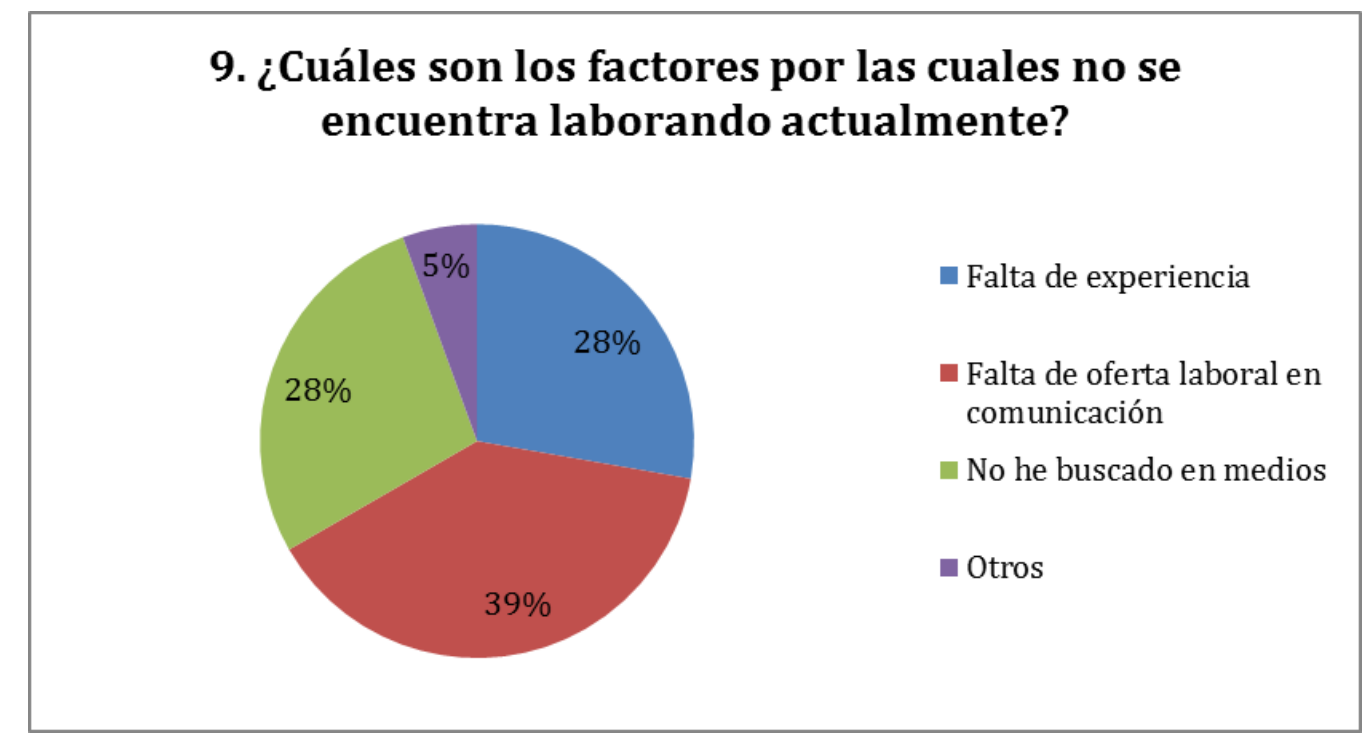




\section{Conclusiones}

Posterior a la realización de la investigación bibliográfica con los autores citados y la aplicación de la metodología expuesta, en el artículo académico se pueden evidenciar varias conclusiones con respecto a la temática de las opciones profesionales que tienen los Comunicadores Sociales en el mercado laboral.

La Comunicación Social se ha transformado por muchos cambios a nivel político, social, laboral y académico. Por la parte política, desde el año 2013 los comunicadores sociales y los medios de comunicación en el ejercicio del trabajo profesional, se enfrentan a la implementación de la Ley Orgánica de Comunicación, que como lo menciona en el Artículo 1, el objetivo principal de esta ley es desarrollar, proteger y regular, en el ámbito administrativo, el ejercicio de los derechos a la comunicación establecidos constitucionalmente. Sin embargo para los profesionales entrevistados los puntos de vista son variados.

- Para los medios privados la Ley Orgánica de Comunicación (LOC) ha generado una gran diferencia en el ejercicio profesional, en comparación a los años anteriores cuando ésta no existía.

- Las sanciones y demandas recibidas obligan al sector a ser mal visto como un sector de oposición, sin embargo ante los hechos los medios cumplen la mayor parte de sus artículos entre ellos el Art. 23, del derecho a la rectificación y el Art. 24, del derecho a la réplica.

- Por parte del medio público, se considera a la LOC, más bien como una herramienta esencial de trabajo que ha permitido defender los derechos del comunicador para ejercer el trabajo profesional.

- Ante la situación de polaridad entre ambos sectores, tanto el medio público y privado, coinciden en el hecho de que esta ley ha permitido reconocer al periodista como un profesional que merece una remuneración justa.

En el ámbito social y laboral, muchos han sido los cambios que ha traspasado el comunicador social hoy en día, desde la inserción de la tecnología como nueva plataforma para conseguir información, hasta la creación de propios medios de comunicación digital que permiten llegar con más facilidad a un público que exige veracidad e información instantánea.

- Con la implementación de la tecnología nacen nuevos métodos para estar en comunicación constante. Quienes participan en ellos no son solo periodistas o comunicadores sociales en general, nacen los "reporteros ciudadanos".

- El mercado publicitario ha sufrido bajas a nivel económico lo cual les ha obligado a reducir sus inversiones en medios tradicionales, lo que ha significado que las plazas de trabajo se reduzcan en los medios de comunicación y ha orientado a los comunicadores a optar por otras áreas afines a la comunicación. 
- El campo ocupacional del comunicador se ha ampliado en distintos escenarios tales como las relaciones públicas, el periodismo digital y community management debido a las exigencias del mercado de estar siempre en contacto con su público más que todo desde las plataformas digitales hasta donde llegan las marcas y medios de comunicación.

- Todas las áreas de comunicación juegan un papel complementario en el espacio de trabajo de modo que es necesario no solo en los medios sino también en las empresas públicas y privadas mantener una comunicación constante desde todas sus plataformas existentes.

- El comunicador social se convierte en alguien recursivo capaz de plantear desde la comunicación distintas estrategias para generar información y resultados. Los comunicadores no pueden solo mantenerse con estar en un espacio o medio de comunicación, en la actualidad la situación del mercado laboral incita al emprendimiento de sus propios medios o programas para darse a conocer con contenidos de calidad y el uso del marketing digital propio de quienes conocen como se mueve el medio digital.

Desde las aulas el panorama también es cambiante, pues al igual que en otros aspectos donde los cambios son inminentes algunas de las Facultades de Comunicación Social de Guayaquil generan cambios consecuentes a la exigencia del mercado laboral.

- Desde el sector público el rediseño de la Facultad de Comunicación hace hincapié en la incorporación de licenciados (2017) que hayan recibido 8 semestres de estudio. La vinculación con la sociedad por medio de proyectos que ayuden a las comunidades a expresarse a través de la comunicación.

- En el sector privado los cambios se rigen a la Clasificación Internacional Normalizada de la Educación (CINE) de la ONU y al Consejo de Educación Superior (CES). Los cuales exigen un rediseño de malla curricular en donde no existan menciones y estrictamente se plantee la comunicación desde todos sus campos de acción, lo cual permitirá tener una comunicación más inclusiva y acorde a los requerimientos en el mercado laboral.

En cuanto a la visión de los medios de comunicación y las distintas áreas para ejercer la comunicación se plantea un perfil profesional para quienes salen al mercado laboral en busca de empleo.

- Lo que esperan los medios de los nuevos comunicadores.- Profesionales que busquen noticias y sepan contarlas, periodistas que tengan ojos para mirarlo todo, curiosidad para interesarse y ganas de acudir a donde está la información. Los periodistas siempre son iguales, lo único que puede cambiar son las herramientas para hacer llegar al público las noticias.

- Con base a los medios tradicionales.- Se considera que más allá de la vocación por comunicar y contar la verdad, el comunicador debe querer estar en servicio constante hacer de su tiempo una plataforma para que la gente sepa cómo obtener la información adecuada. 
- El comunicador debe estar cada vez más con las herramientas de campo a la mano, y utilizarlas del modo que esté en contacto directo con su público.

- Un método en crecimiento.- Se crea la tendencia de que el periodista no solo busca adentrarse en primer lugar a un medio de comunicación tradicional para que su trabajo se difunda, ya que, por medio de las redes sociales existe la posibilidad de generar trabajos, investigaciones y exposiciones de sus entrevistas. (Periodismo digital).

- Mercado comunicacional saturado.- El campo laboral del comunicador en un país en aras de desarrollo como Ecuador, no es tan amplio, a diferencia otros países las facilidades no son las mismas y quienes aspiran por entrar a un puesto no poseen la experiencia necesaria.

- Otras áreas de comunicación.- Relaciones Públicas, Comunicación Organizacional y Community Management, son opciones de trabajo y crecimiento profesional en donde se tiene contacto constante con los medios de comunicación, el público y la comunicación interna de las empresas e instituciones.

Finalmente, en el campo de la comunicación social no existe un dato estadístico que demuestre la situación laboral del profesional. Lo que encontramos en las diferentes páginas vinculadas al gobierno como SECOM ${ }^{8}$ y CORDICOM $^{9}$ son archivos y documentos basados en la profesionalización de trabajadores de medios de comunicación que antes no tenían su título profesional y la implementación de medios comunitarios en sectores rurales. Sin embargo y según el registro anual del Ministerio de Trabajo en la Encuesta Nacional de Empleo, Desempleo y Subempleo hasta diciembre del 2016, la tasa de desempleo alcanzó el 5,2\% a nivel nacional.

\section{Bibliografía}

Ministerio de Trabajo. (s.f.). Ministerio de Trabajo. Recuperado el 21 de Enero de 2017, de http://www.ecuadorencifras.gob.ec/documentos/web-inec/EMPLEO/2016/Diciembre2016/122016_Presentacion_Laboral.pdf

Aced, C. (2013). Relaciones públicas 2.0: cómo gestionar la comunicación corporativa en el entorno digital. Barcelona, ES: Editorial UOC.

Barbero, J. M. (2009). Los oficios del comunicador. Revista de Humanidades - Universidad EAFIT, 2(002)

Barquero, J. D. (2005). Comunicación estratégica: relaciones públicas, publicidad y marketing (1a. ed.). Madrid, España.

\footnotetext{
${ }^{8}$ Secretaría Nacional de Comunicación(SECOM)

${ }^{9}$ Consejo de Regulación y Desarrollo de la Información y Comunicación.(CORDICOM)
} 
Burgueño, J. M. (2014). Comunicación institucional para periodistas: manual práctico de comunicación y relaciones públicas. Barcelona: Editorial UOC.

Caloca Carrasco, E. (2010). Recuento histórico del periodismo. México, DF: Instituto Politécnico Nacional.

Calvo Roy, J. (13 de Octubre de 2006). Vargas Llosa: "El periodismo es el mayor garante de la libertad". Nueva York.

Castillo Ochoa, E., \& Tapia Fonllen, M. (2006). La formación de comunicadores ante los nuevos retos. México, D.F: Red Perfiles Educativos.

Com, S., Ackerman, S. E., \& Morel, M. P. (2011). Introducción a la comunicación. Buenos Aires, Argentina: Ediciones del Aula Taller.

Delgado, C. (2008). Versión beta: tendencias de la prensa y el periodismo del siglo XXI en Venezuela. Venezuela: UCAB - El Nacional.

Echeverría, M. C., \& Viada, M. M. (2014). Periodismo en la web, lenguajes y herramientas de la narrativa digital. Córdoba, Argentina: Editorial Brujas.

Eggers-Brass Teresa, G. M. (2010). Cultura y comunicación. Buenos Aires (Ituzaingó), Argentina: Editorial Maipue.

Española, R. A. (s.f.). Real Academia Española. Recuperado el 29 de Diciembre de 2016, de http://dle.rae.es/?id=SdXSbMM

Genova, E. D. (2000). Manual de relaciones públicas e institucionales: estrategias de comunicación y tácticas relacionales: estrategias de comunicación y tácticas relacionales. Buenos Aires, Argentina: Ugerman Editor.

Ibañez San Millán, M. (2014). Redes sociales para PYMES: Introducción al Community Management. España: Ministerio de Educación de España.

Jiménez, A. (2013). Comunicación. Madrid, España: Ediciones Díaz de Santos.

Marquina, J. (2013). Plan social media y community manager. Barcelona, ES: Editorial UOC.

Moragas, M. (2009). Cambios en la comunicación, cambios en los estudios de comunicación. . Bogotá, CO: Red Signo y Pensamiento.

Rebeil Corella, M. A. (1998). El poder de la comunicación en las organizaciones. . México, D.F: Plaza y Valdés, S.A. de C.V.

Rivas, M. (2009). Tecnología y medios de comunicación: ¿cambio en los métodos o en los contenidos? Buenos Aires: El Cid Editor. 
Vilches Vivancos, F. S. (2014). Comunicación social y accesibilidad. Madrid, España: Editorial Dykinson.

Villegas, M. C. (2014). Comunicación empresarial: plan estratégico como herramienta gerencial y nuevos retos del comunicador en las organizaciones (2a ed.). Bogotá, Colombia: Editorial UOC. 